\title{
Effect of the North Equatorial Counter Current on the generation and propagation of internal solitary waves off the Amazon shelf (SAR observations)
}

\author{
J. M. Magalhaes ${ }^{1}$, J. C. B. da Silva ${ }^{1}$, M. C. Buijsman ${ }^{2}$, and C. A. E. Garcia ${ }^{3}$ \\ ${ }^{1}$ CIMAR/CIIMAR - Interdisciplinary Centre of Marine and Environmental Research \& Department of Geosciences, \\ Environment and Spatial Planning, University of Porto, Rua dos Bragas 289, 4050-123 Porto, Portugal \\ ${ }^{2}$ University of Southern Mississippi, Department of Marine Science, 1020 Balch Blvd, Stennis Space Center, MS 39529, USA \\ ${ }^{3}$ Federal University of Rio Grande, Av. Itália, 96201-900, Caixa Postal 474, Rio Grande, Brazil
}

Correspondence to: J. M. Magalhaes (jmagalhaes@fc.ul.pt)

Received: 1 October 2015 - Published in Ocean Sci. Discuss.: 27 October 2015

Revised: 5 January 2016 - Accepted: 27 January 2016 - Published: 12 February 2016

\begin{abstract}
Synthetic aperture radar (SAR) imagery from the Amazon shelf break region in the tropical west Atlantic reveals for the first time the two-dimensional horizontal structure of an intense Internal Solitary Wave (ISW) field, whose first surface manifestations are detected several hundred kilometres away from the nearest forcing bathymetry. Composite maps and an energy budget analysis (provided from the Hybrid Coordinate Ocean Model - HYCOM) help to identify two major ISW pathways emanating from the steep slopes of a small promontory (or headland) near $44^{\circ} \mathrm{W}$ and $0^{\circ} \mathrm{N}$, which are seen to extend for over $500 \mathrm{~km}$ into the open ocean. Further analysis in the SAR reveals propagation speeds above $3 \mathrm{~m} \mathrm{~s}^{-1}$, which are amongst the fastest ever recorded. The main characteristics of the ISWs are further discussed based on a statistical analysis, and seasonal variability is found for one of the ISW sources. This seasonal variability is discussed in light of the North Equatorial Counter Current. The remote appearance of the ISW sea surface manifestations is explained by a late disintegration of the internal tide (IT), which is further investigated based on the SAR data and climatological monthly means (for stratification and currents). Acknowledging the possibility of a late disintegration of the IT may help explain the remote-sensing views of other ISWs in the world's oceans.
\end{abstract}

\section{Introduction}

Research efforts concerning Internal Waves (IWs) are often motivated by satellite observations, which have the unique ability to render their two-dimensional horizontal structure (see e.g. Osborne and Burch, 1980; Alpers and Salusti, 1983; Apel et al., 1985; New and da Silva, 2002; Sherwin et al., 2002; Ramp et al., 2004; Grisouard et al., 2011; Guo et al., 2012; Jackson et al., 2012; Mercier et al., 2012; Kozlov et al., 2014). Both new and unidentified IW hotspots, as well as previously studied regions, have benefited from satellite views, frequently providing new and deeper insights into their generation, propagation and dissipation mechanisms (e.g. Zhao et al., 2004; Vlasenko and Alpers, 2005; Azevedo et al., 2006; Magalhaes et al., 2012) - see also http://jmagalhae0. wix.com/internal-waves-. Data synergy, including in situ measurements and numerical modelling, has also contributed to bridge IWs across multidisciplinary frameworks, spanning from fundamental oceanography to important applications (see e.g. review papers by Garret and Kunze, 2007; Lamb, 2014; Alford et al., 2015). For instance, open questions still remain concerning global tide energy dissipation, in particular that owing to IWs, which are important in ocean mixing and climate studies (see e.g. Zhao et al., 2012; Alford et al., 2015).

A regained interest has also come from acknowledging IWs as one of the available mechanisms by which mass and momentum are transported in the oceans, while recognizing that sources and sinks may be significantly far apart (see e.g. 
Moum et al., 2007; Ferrari and Wunsch, 2009; Shroyer et al., 2010; Zhang et al., 2015). Satellite altimetry studies (see e.g. Ray and Cartwright, 2001) have indeed confirmed propagating distances of the order of $1000 \mathrm{~km}$ for the long internal tides (ITs, i.e. IWs of tidal frequency), and shorter-scale Internal Solitary Waves (ISWs) have been shown by other remote-sensing methods to propagate considerable distances as well (e.g. da Silva et al., 2011; Guo et al., 2012).

The Amazon shelf break is an important source for intense ITs (see Fig. 1 for location) as was early recognized in the work of Baines (1982) - exceeded only by the classical Bay of Biscay and the more recently studied South China Sea (see his Fig. 10). Similar results can be equally found in more recent models, which also feature the Amazon shelf break as an important hotspot for the conversion of barotropic to baroclinic energy (see e.g. Buijsman et al., 2016). The presence of ITs and ISWs has already been documented with in situ measurements (Ivanov et al., 1990; Brandt et al., 2002; Vlasenko et al., 2005) and acknowledged in remote-sensing data (see also Jackson, 2004), but no detailed description has yet emerged regarding the two-dimensional horizontal structure of the ISW field.

Previous studies include the work by Ivanov et al. (1990) documenting IT energetics across the North Equatorial Counter Current (NECC). According to these authors, a decrease of energy density in the semi-diurnal IT was found close to the core of the NECC, presumably owing to energy transfers to smaller-scale IWs (reported visually by the onboard crew). More than a decade later, Brandt et al. (2002) confirmed the existence of large-amplitude ISWs in this region, using high-resolution acoustical data (collected during November 2000). In their study, ship-mounted acoustic Doppler current profiler (ADCP) measurements along a meridional section (coincident with the NECC; see Fig. 1 for location) were used to measure the waves' main properties. Their findings included dominant directions close to $30^{\circ} \mathrm{T}$ and inter-packet distances of the order of $70 \mathrm{~km}$. More recently, Vlasenko et al. (2005) also reported on data collected close to generation site A in Fig. 1 (during November 1980). According to these last authors, a density front was found in this region of the tropical west Atlantic (see Fig. 1 and their Figs. 3.1 and 3.2), which is associated with the NECC. A very similar setting is also discussed in the South China Sea by Buijsman et al. (2010a), where the Kuroshio Current is also associated with a density front, with important implications for ISW development there. This feature is of particular interest to this study, and its implications are further discussed in Sect. 3.

The specific location of the Amazon shelf break region adds further motivations to the oceanographic framework. It is placed in the tropical west Atlantic together with an intricate current system, including two major ocean currents the NECC and the North Brazilian Current (NBC; see Fig. 1 for locations). These are found very close to the Amazon River mouth, which accounts for up to one-fifth of the to-

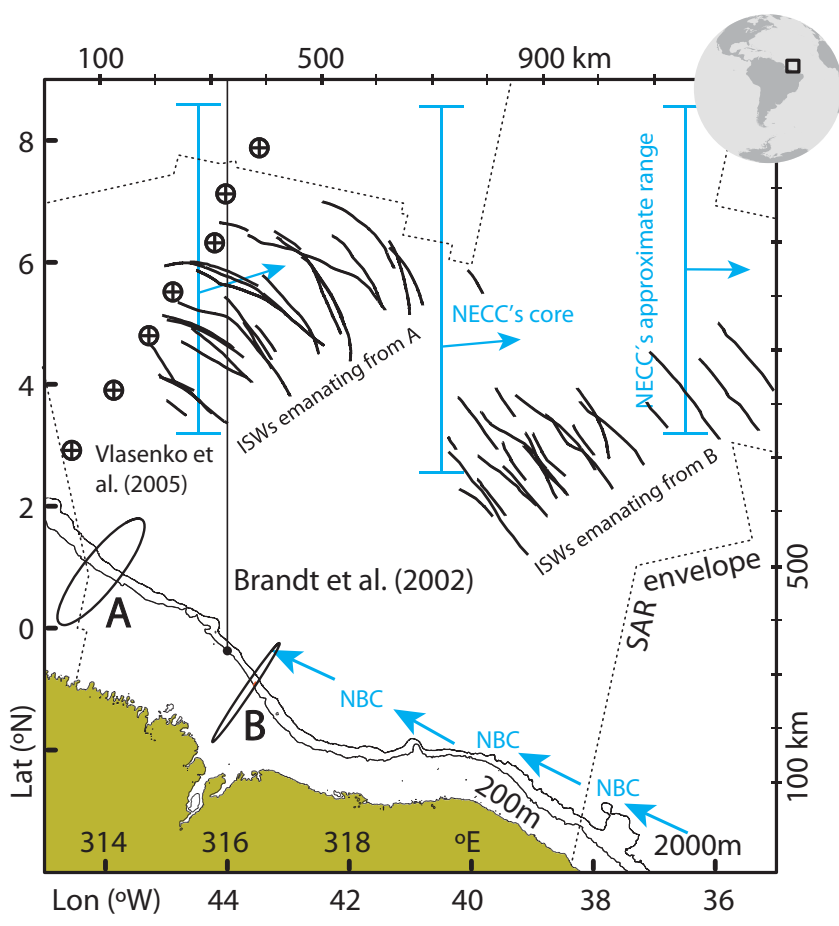

Figure 1. ISW composite map (see inset for location in the tropical west Atlantic) with SAR observations limited to the dashed black envelope. Two major current systems are depicted in blue arrows: the North Brazilian Current (NBC) and the North Equatorial Counter Current (NECC), with vertical solid lines indicating its approximate range across the study region. Tidal ellipses in black are representative of sites $\mathrm{A}$ and $\mathrm{B}$ (scaled to a maximum current of $0.5 \mathrm{~m} \mathrm{~s}^{-1}$ in the across-shelf direction), which represent key areas of ISW generation on either side of a small promontory (near 44 and $0^{\circ} \mathrm{N}$ ). The shelf break is highlighted by the 200 and $2000 \mathrm{~m}$ isobaths (in black lines). A meridional section along $44^{\circ} \mathrm{W}$ used in Brandt et al. (2002) is shown for reference, together with the approximate location of a series of CTD stations (see circles with black crosses) discussed in Vlasenko et al. (2005).

tal freshwater input into the world's oceans (see e.g. Wisser et al., 2010). The NECC is highly variable, featuring a strong annual cycle (see e.g. Garzoli and Katz, 1983) and significant inter-annual variability in its mean location and strength (Hormann et al., 2012). In fact, the NECC includes a seasonal reverse cycle in the east-westward direction (see e.g. Garzoli and Katz, 1983, for further details), which will be shown to have a major influence in the propagation of ISWs.

The ISWs presented in this study will be shown to propagate over considerable distances across major oceanic current systems. The Amazon shelf break is particularly interesting because low-mode ITs generated at the shelf break and propagating into the open ocean may interact with eddies and the meandering field of steady currents such as the NBC and the NECC. Dunphy and Lamb (2014) showed that passing a mode-one IT through a mode-one baroclinic eddy results in IW scattering into higher modes - with implications for the 
redistribution of energy onto smaller scales. Moreover, their proximity with a major freshwater source also conveys an additional interest with possible implications for climatology, biology and engineering-related fields of study - owing for instance to changes in near-surface stratification (i.e. mixing) or substantial discharges of suspended sediments (see Johns et al., 1998; Almeida-Filho et al., 2005).

The present study is therefore aimed at a first account of the full two-dimensional horizontal structure of the ISW field off the Amazon shelf. The remainder of the paper follows, with Sect. 2 describing the new satellite observations of short-period ISWs in the study region, together with preliminary interpretations of their main features and a statistical analysis of their horizontal structure. Section 3 follows with discussions on the generation and propagation. A summary and some concluding remarks are presented in the final section of the paper.

\section{SAR imagery analysis}

Synthetic aperture radars (SARs) have proven very useful amongst other means of satellite imagery which are typically used to survey ISWs, owing mainly to their extensive field of view along with detailed spatial resolution. In particular, wide-swath acquisitions (WS) from the Envisat ASAR (Advanced Synthetic Aperture Radar) have nominal spatial resolutions of $75 \mathrm{~m}$, while covering large areas of approximately $400 \times 400 \mathrm{~km}^{2}$. This makes them ideal to observe multiple packets of large ISWs, which are usually separated by semidiurnal wavelengths (of the order of $100 \mathrm{~km}$ ). Indeed, the ISW sea surface manifestations depicted in SAR imagery are now widely documented in the literature and are essentially a result of hydrodynamic modulation of the sea surface roughness and wave breaking, provided that the wind speeds are not excessively strong (see e.g. Alpers, 1985; da Silva et al., 1998; Kudryavtsev et al., 2005).

A representative data set was assembled based on 17 SAR images, all of which belonging to the Envisat ASAR and acquired in WS mode (all showing evidence of ISWs). These range from 2004 to 2012 with no seasonal preferences being considered, since favourable stratification conditions for ISWs occur year-round in equatorial regions (see Table 1 for more details). The data set was also chosen to provide a fair coverage of the semi-diurnal $\left(\mathrm{M}_{2}\right)$ and fortnightly tidal cycles. This is best seen in Fig. 2, which presents tidal heights for each acquisition (as listed in Table 1, according to Egbert and Erofeeva, 2002) and therefore offers an overall view of the data set with ISWs being observed both in neap and spring tides. Therefore, unlike other regions where high ISW activity is imaged mostly during spring tides (e.g. the Mascarene Ridge; see da Silva et al., 2011), these observations are not clustered around some particular phase of the floodebb tidal cycle (the latter effect being a consequence of sunsynchronous orbits; e.g. Valente and da Silva et al., 2009).

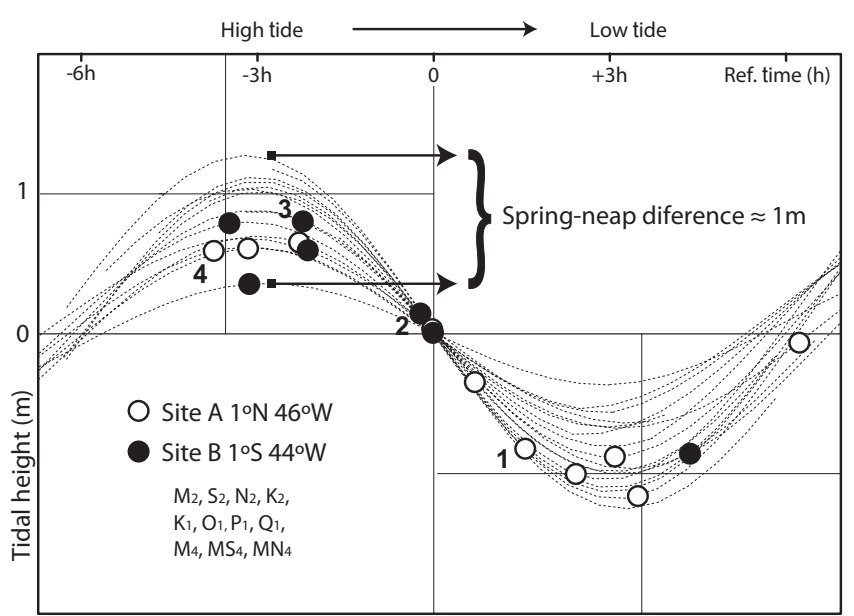

Figure 2. Semi-diurnal and fortnightly tidal phases for all dates and times listed in Table 1 (each corresponding to an image acquisition), using the tidal constituents listed in the bottom-left corner, and computed correspondingly at locations A and B (represented by white and black circles, respectively). Note that, for a meaningful comparison, the time running in the horizontal direction is with reference to the transition between high tide and low tide (i.e. when tidal heights change sign), and differences in the vertical range concern different phases of the spring-neap cycle.

Figure 1 presents a comprehensive view of the study region, together with a composite map resulting from the 17 acquisitions listed in Table 1, and whose envelope is shown by the black dashed line. For clarity, only the strongest ISW signatures were considered and only the leading wave is depicted for each ISW packet (in black solid lines, with a total of 59 packets being represented). A well-organized ISW field can be seen running along two major pathways apparently associated with distinct hotspots, which have been labelled A and $\mathrm{B}$ close to the $200 \mathrm{~m}$ isobath (representative tidal ellipses have been drawn for reference). The wave surface manifestations are fairly aligned with the steep slopes on either side of a small promontory approximately at $44^{\circ} \mathrm{W}$ and $0^{\circ} \mathrm{N}$, and therefore appear to emanate from localized, and yet distinctive, regions of the shelf break (to be further discussed in Sect. 3).

Typical SAR views of the study region are given in Fig. 3. Both case studies reveal characteristic sea surface manifestations of intense ISWs appearing more than $500 \mathrm{~km}$ away from the nearest coastline (see insets for locations). Further inspection of the SAR signatures, in the same fashion as Thompson and Gasparovic (1986), indicates multiple wave packets propagating offshore and into the open ocean with a strong northeast component. The average inter-packet distance ranges from 121 to $140 \mathrm{~km}$, which are typical wavelengths of long (semi-diurnal) ITs of the fundamental mode. Therefore, ISW packets have been labelled assuming generation in consecutive semi-diurnal cycles, and they appear in sequence beginning from $0 \mathrm{M}_{2}$ to $2 \mathrm{M}_{2}$ in Fig. $3 \mathrm{~b}$, and to $4 \mathrm{M}_{2}$ 
Table 1. List of all Envisat ASAR images (in wide-swath mode) used in this study and depicted in Fig. 1, along with dates and times of acquisition and the respective generation site (i.e. A or B). Times after high water (TAHW - taken accordingly at sites A and B) are shown together with tidal heights and ranges, indicating each image's tidal phase within the semi-diurnal and fortnightly tidal cycles, respectively.

\begin{tabular}{|c|c|c|c|c|}
\hline Date & $\begin{array}{l}\text { Time } \\
\text { (UTC) }\end{array}$ & Site & $\begin{array}{l}\text { TAHW } \\
\text { (h) }\end{array}$ & $\begin{array}{l}\text { Tidal height and } \\
\text { range }(\mathrm{m})\end{array}$ \\
\hline 22 Feb 2012 & $12 \mathrm{~h} 42 \mathrm{~min}$ & $\mathrm{~A}$ & +4.5 & -0.83 and 2.25 \\
\hline 26 Jan 2012 & $12 \mathrm{~h} 32 \mathrm{~min}$ & $\mathrm{~B}$ & +2.7 & +0.13 and 2.00 \\
\hline 16 Dec 2011 & $12 \mathrm{~h} 35 \mathrm{~min}$ & $\mathrm{~B}$ & +0.8 & +0.78 and 1.74 \\
\hline 2 Dec 2011 & $12 \mathrm{~h} 48 \mathrm{~min}$ & A & -0.6 & +0.059 and 1.34 \\
\hline 2 Nov 2011 - in Fig. 3a & $12 \mathrm{~h} 48 \mathrm{~min}$ & A & -0.1 & +0.61 and 1.40 \\
\hline 25 Oct 2011 & $12 \mathrm{~h} 41 \mathrm{~min}$ & A & +5.8 & -1.15 and 2.46 \\
\hline 14 Oct 2011 & $14 \mathrm{~h} 44 \mathrm{~min}$ & A & +5.8 & -0.88 and 1.88 \\
\hline 6 Oct 2011 & $12 \mathrm{~h} 37 \mathrm{~min}$ & $\mathrm{~B}$ & -3.3 & -0.11 and 1.35 \\
\hline 3 Oct 2011 - in Fig. 9 & $12 \mathrm{~h} 47 \mathrm{~min}$ & A & +0.7 & +0.65 and 1.48 \\
\hline 10 Aug 2011 & $12 \mathrm{~h} 26 \mathrm{~min}$ & $\mathrm{~B}$ & +5.2 & -0.85 and 1.74 \\
\hline 27 May 2009 - in Fig. 9 & $12 \mathrm{~h} 41 \mathrm{~min}$ & A & +3.1 & +0.01 and 2.53 \\
\hline 25 May 2009 & $01 \mathrm{~h} 12 \mathrm{~min}$ & $\mathrm{~A}$ & +5.8 & -1.00 and 2.22 \\
\hline 11 May 2009 & $12 \mathrm{~h} 44 \mathrm{~min}$ & $\mathrm{~A}$ & +3.9 & -0.36 and 2.04 \\
\hline $25 \mathrm{Jul} 2005$ & $01 \mathrm{~h} 12 \mathrm{~min}$ & $\mathrm{~B}$ & +2.9 & -0.01 and 2.19 \\
\hline 14 Apr 2005 & $12 \mathrm{~h} 10 \mathrm{~min}$ & $\mathrm{~B}$ & +1.1 & +0.60 and 1.32 \\
\hline 6 Sep 2004 - in Fig. 3b & $12 \mathrm{~h} 25 \mathrm{~min}$ & $\mathrm{~B}$ & -0.3 & +0.35 and 0.91 \\
\hline 25 Jul 2004 & $00 \mathrm{~h} 44 \mathrm{~min}$ & $\mathrm{~B}$ & -0.3 & +0.80 and 1.60 \\
\hline
\end{tabular}

in Fig. 3a. These average inter-packet distances can be converted into mean propagation speeds, since a semi-diurnal generation is being assumed. In this case Fig. 3 reveals these waves to be ranked amongst the fastest ever recorded, with mean values ranging from 2.7 to $3.1 \mathrm{~m} \mathrm{~s}^{-1}$ (for locations $\mathrm{B}$ and $\mathrm{A}$, respectively).

Corresponding normalized backscatter intensities (i.e. ( $I$ $\left.I_{0}\right) / I_{0}$ ) taken across representative ISWs in Fig. 3 are presented in Fig. 4, which are characteristic of the study region. We note that profiles were taken in the same fashion as in da Silva et al. (2011), with backscatter intensities ( $I$ ) being computed along a rectangular transect perpendicular to the wave packet and normalized by some unperturbed mean value $\left(I_{0}\right)$ usually taken ahead of the ISWs (see Fig. 3b for an example). We further note that both case studies in Fig. 3 were selected to have low-wind-speed components along the directions of wave propagation. In Fig. 4, large-scale individual waves are seen propagating in the deep ocean, with horizontal scales (e.g. given by $L$ in Fig. 4 ) of approximately 5 and $12 \mathrm{~km}$, for $\mathrm{A}$ and $\mathrm{B}$, respectively.

To further investigate the main characteristics of the ISW field, we now present a statistical analysis, done for a sample of 59 different packets collected from the 17 images listed in Table 1. Figure 5 begins with a distribution of the alongcrest coherence lengths (or crest lengths), and it can be seen that it is slightly skewed towards the lower end, with values ranging up to more than $200 \mathrm{~km}$ for waves coming from both locations A and B (see also Fig. 1). Overall, the majority of the observations are characterized by crest lengths around $150 \mathrm{~km}$, which make them comparable with other large-scale observations in the world's oceans (see e.g. New and da Silva, 2002; Ramp et al., 2004; da Silva et al., 2011; Magalhaes et al., 2012). Figure 6 is also indicative of the presence of large-scale ISWs as it shows the distribution of the characteristic soliton widths $(L)$. These were estimated as illustrated in Fig. 4 (see also Fig. 3), as is typically done for sea surface manifestations of ISWs in SAR images (see e.g. da Silva et al., 1998). The length scale $L$ is considered here to be a proxy measure of the horizontal dimension of the individual solitary waves (along their propagation direction). We note that for this particular study region the majority of the case studies presented ISWs with positive backscatter variations from the unperturbed $I_{0}$ (as is defined in da Silva et al., 1998; see their Fig. 3), and hence $L$ was generally defined as the length where normalized backscatter intensities are greater than $I_{0}$ (see dashed lines and $L$ in Fig. 4). The characteristic soliton widths found in Fig. 6 are of the order of several kilometres, with mean distribution values amounting to 5 and $6 \mathrm{~km}$ for sites A and B, respectively, and hence an order of magnitude higher when compared, e.g., with the Bay of Biscay, Massachusetts Bay or the western Iberian shelf (Azevedo et al., 2006; da Silva and Helfrich, 2008; Magalhaes and da Silva, 2012). Consistently with case studies analysed in Fig. 3, the distribution in Fig. 7 also reveals that few waves are found per wave packet. In fact, their distribution is strongly biased towards the lower end, with the majority of values ranging from one to two solitons per packet (for both sites A and B). Finally, Fig. 8 presents a distribution concerning the main directions of wave propagation found in the study region, for both locations A and B. As seen in Fig. 8a, 

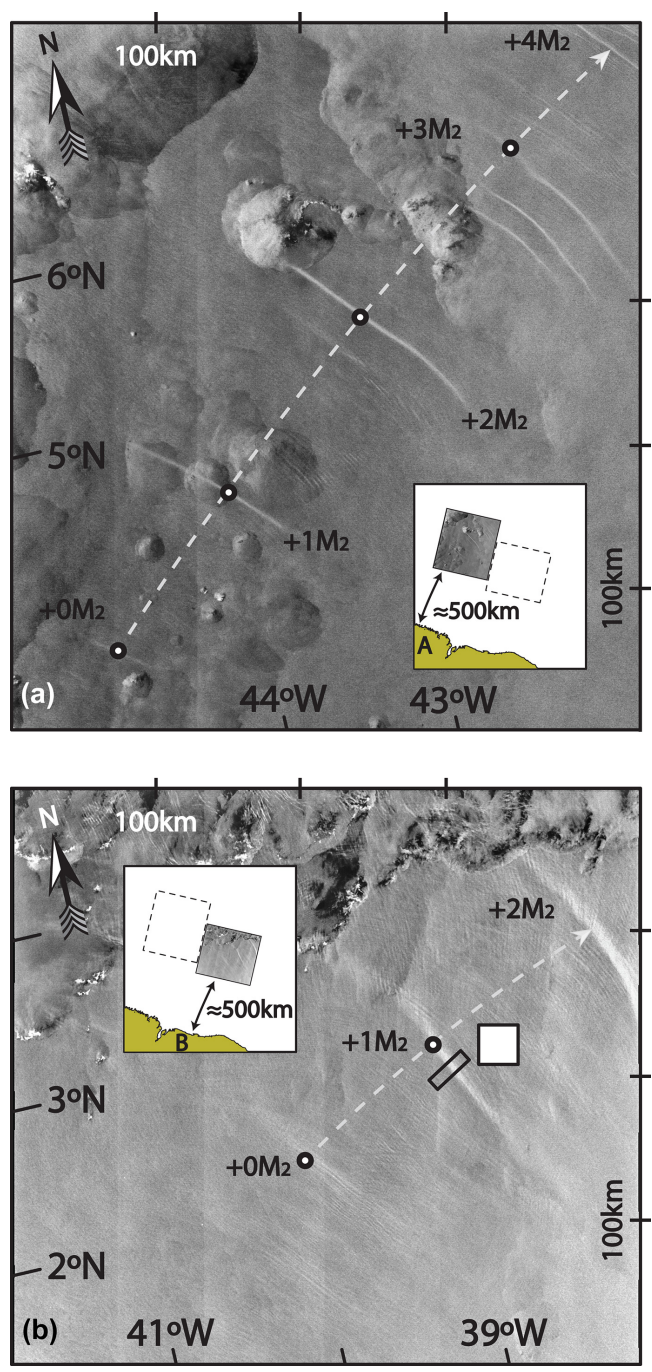

Figure 3. (a) Subset of a SAR image dated 2 February 2011 (acquired at $12 \mathrm{~h} 47 \mathrm{~m}$ ) showing ISW packets emanating from location A, and labelled sequentially from $0 \mathrm{M}_{2}$ to $4 \mathrm{M}_{2}$ (with $4 \mathrm{M}_{2}$ being only partially imaged). An inset shows the image location with respect to the coastline, and the dashed line shows the location of Fig. $3 b$ for comparison. (b) As in top panel but for a SAR image dated 6 September 2004 (acquired at 12 h $25 \mathrm{~m}$ ) and showing ISWs packets emanating from location B. The black rectangle and white-filled square are examples of a radar backscatter transect and mean unperturbed background. A north-pointing arrow and distance scales are added on the top and right-hand sides of both images.

the waves generally travel to the northeast, with waves from location A having a slightly more northern component than those from location B (as is also seen in Fig. 3). In addition, the pathway from location B is somewhat narrower (i.e. between 45 and $60^{\circ} \mathrm{T}$ ) when compared with the wider range of directions for ISWs coming from location A (i.e. between 30 and $60^{\circ} \mathrm{T}$ ). Fig. $8 \mathrm{~b}$ further reveals that this wider range of directions comes in fact from a seasonal variation. It shows that waves emanating from A between February and May

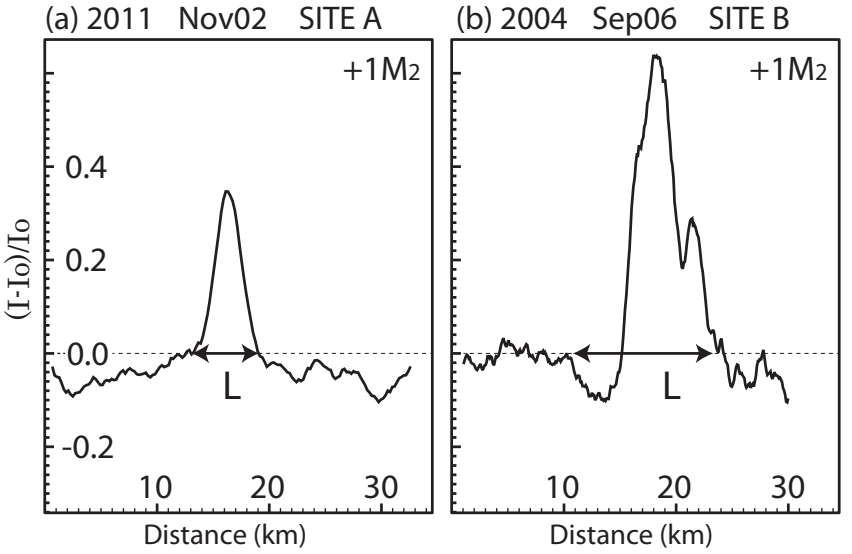

Figure 4. Normalized backscatter intensity profiles corresponding to representative wave packets in Fig. 3a (left panel) and b (right panel). See Fig. 3b for a representative radar backscatter transect (used to compute $I$ ) and corresponding mean unperturbed background (used to compute $I_{0}$ ). A measure of the waves' horizontal dimensions is given in both panels (i.e. $L$; see text for more details).

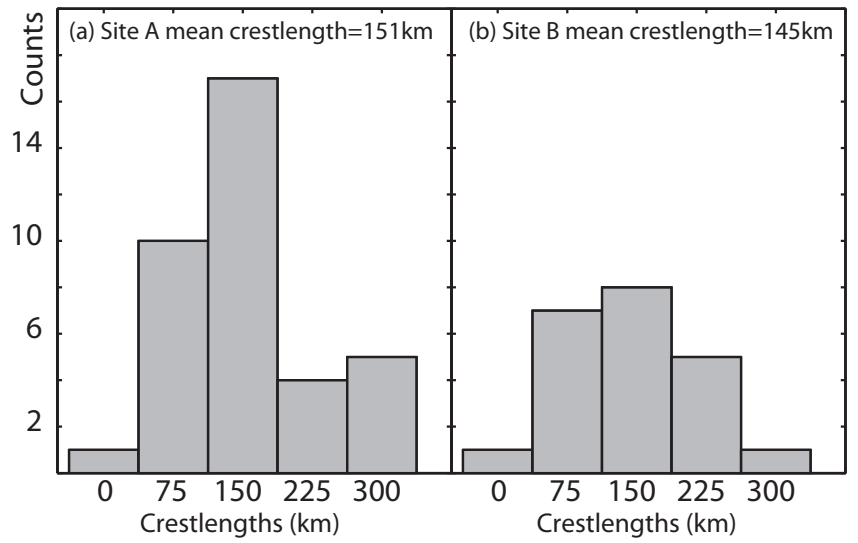

Figure 5. Crest length distribution for the leading ISWs in each packet.

seem to propagate steadily towards $30^{\circ} \mathrm{T}$, but those between July and December have more northeasterly directions between 30 and $60^{\circ} \mathrm{T}$. We note that no seasonal variability was found for waves associated with location B.

The SAR imagery highlights several important results concerning the two-dimensional horizontal structure of the ISW field in this region. In particular the composite map clearly reveals the existence of different pathways associated with two nearby and yet distinct locations (labelled A and B in Fig. 1). Moreover, the satellite data reveal a seasonal variability in the directions of propagation for location A. Another puzzling feature is that, unlike typical observations from other marginal seas, the ISW sea surface manifestations appear quite far from the nearest continental shelves - as far as $500 \mathrm{~km}$ in comparison with distances of approximately $100 \mathrm{~km}$ in other regions (e.g. in the Mozambique Channel; 


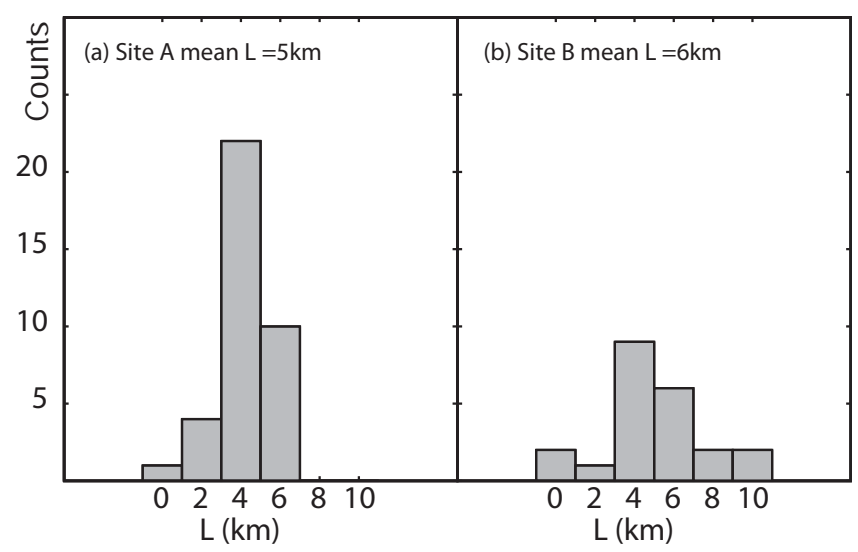

Figure 6. Soliton width $(L)$ distribution for the leading ISWs in each packet.

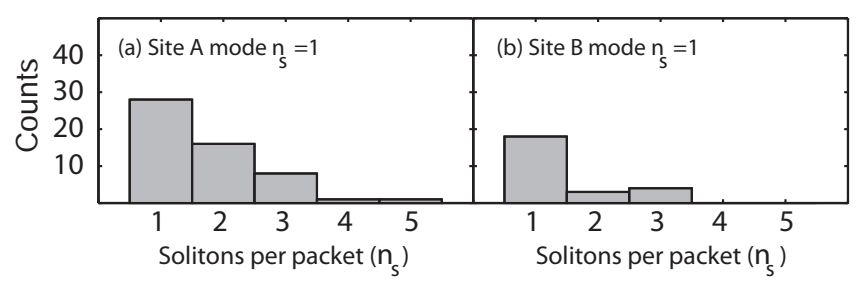

Figure 7. Distribution of number of solitary waves per packet $\left(n_{\mathrm{S}}\right)$.

see da Silva et al., 2009). These and other results are to be discussed in the next section.

\section{Discussions}

We now discuss in more detail some of the results of the SAR image analysis. In particular, seasonal differences are investigated with respect to the NECC's variability, and the remote appearance of the ISW sea surface manifestations is discussed in the light of an unusually large disintegration timescale of the IT.

\subsection{Seasonal variability in the SAR data}

Internal waves emanating from A (Fig. 1) can be further divided into two subsets according to their season. It was found that waves between February and May had a different and more straightforward path when compared with those between July and December - with January and June being somewhat transition months.

Figure 9a highlights the seasonal variability between the internal waves. In green and blue colours are two representative case studies corresponding to generation site A, one dated 27 May 2009 (in green) and another dated 3 October 2011 (in blue). Note that waves from location B are also shown for reference (those from Fig. 3b) - although they do not reveal significant seasonal variability and will no longer be discussed for that matter. These two case studies illustrate
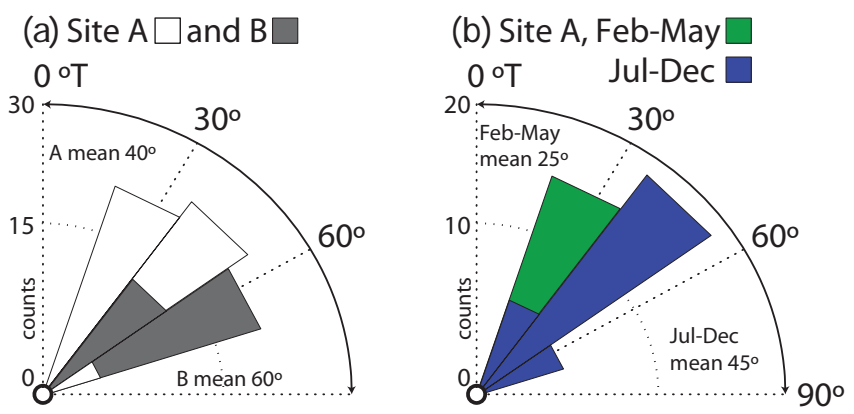

Figure 8. Propagation direction distribution for each packet of ISWs.

the differences in the ISW propagation characteristics, which were otherwise not apparent in the overall view of Fig. 1. Apart from being refracted towards the east (also seen to a lesser extent in Fig. 3a for November), the October case study shows an increase in the ISW inter-packet separations, associated with an increase in their average propagation speed (of more than $30 \%$ when comparing the $3.4 \mathrm{~m} \mathrm{~s}^{-1}$ in October with the $2.4 \mathrm{~m} \mathrm{~s}^{-1}$ in May), which also seems to enable them to penetrate further into the open ocean - note only leading waves are depicted (as in Fig. 1).

According to Fig. 9a, these differences appear to be related to the seasonal variability of the NECC, which is represented by the coloured arrows marked along the waves' paths (in green and blue for May and October, respectively). These arrows are representative of the NECC within the bulk of the thermocline (i.e. vertically averaged; see also Fig. 11) and were obtained from monthly mean climatological data (between 1980 and 2011) - provided from NOAA/OAR/ESRL PSD, Boulder, Colorado, and available at http://www.esrl. noaa.gov/psd/data/gridded/.

Between July and December (represented as the October data in blue) ISWs refract eastwards owing to the NECC, which not only acts to refract the waves but also provides an additional current component in the along-ISW propagation direction, contributing to their observed increased propagation speeds and ultimately to their extended penetration farther to the northeast. At the same time the other regime in the NECC (i.e. from February to May and represented as the May data in green) is quite the opposite. The NECC does not flow east, and refraction decreases as the currents weaken substantially during that period, to the point where currents reverse. Instead of contributing with an along-ISW current component, the NECC changes direction so that the flow is now in the opposite direction, running nearly perpendicularly to the ISW direction of propagation, causing ISWs to decelerate along their propagation path. Note also that changes in the NECC are not as strong when considering the ISWs associated with location $\mathrm{B}$. That is probably because $\mathrm{B}$ generated waves only partially intersect the NECC (i.e. along its south- 


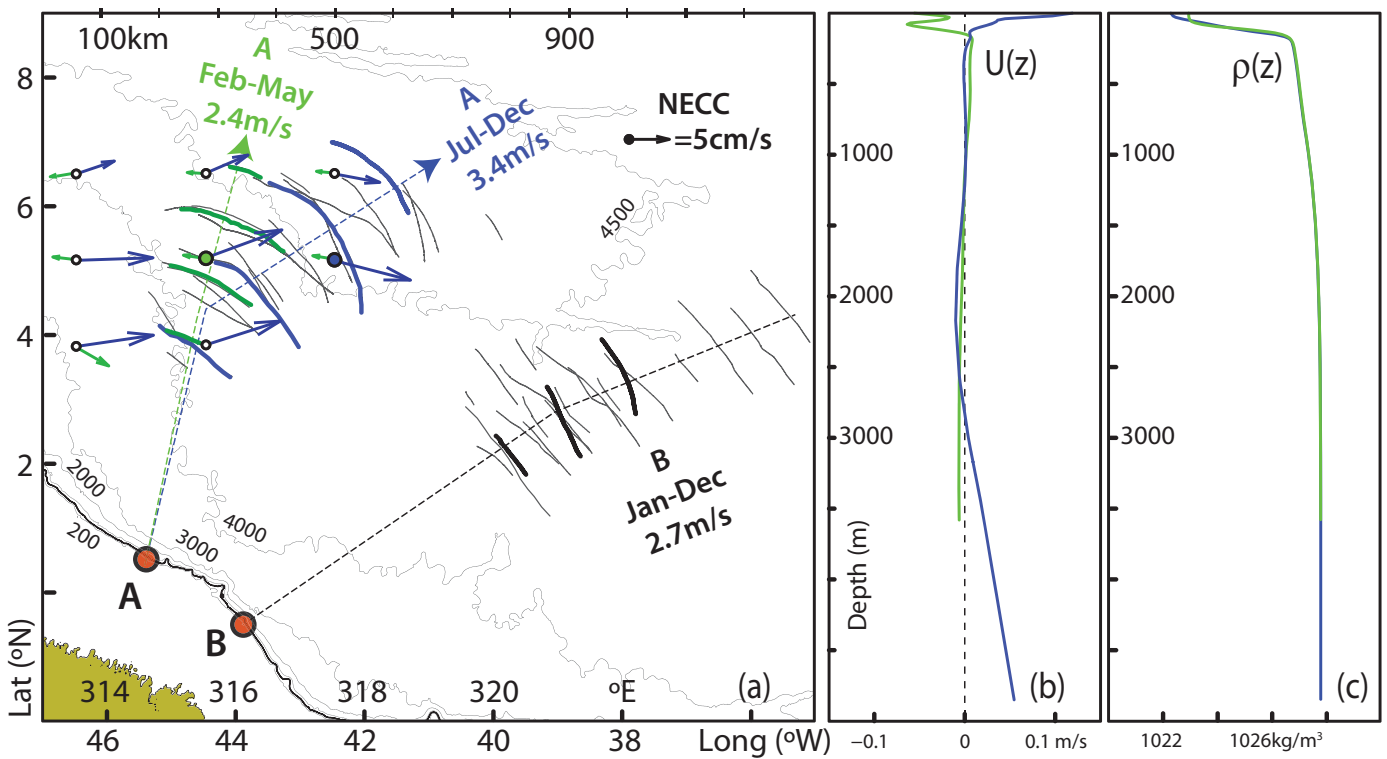

Figure 9. (a) Same composite map as in Fig. 1 is shown in thin black lines, with two case studies highlighted in thick coloured lines, corresponding to location A and representative of two different seasons: from February to May (in green and dated 27 May 2009) and from July to December (in blue and dated 3 October 2011). Their averaged propagation speeds are also indicated along with idealized propagation paths (in thin dashed lines). Corresponding NECC monthly means (in green and blue for May and October, respectively) are shown to depict its seasonal character along the ISW propagation paths (see also scaled arrow in black). For reference, the case study shown in Fig. 3b is also highlighted in thick black lines, along with its mean propagation speed. Depth contours for 200, 500, 1000, 2000, 3000, 4000, and 4500 m are given in thin grey lines. Note the 200 and $1000 \mathrm{~m}$ contours are hardly distinguishable from the $500 \mathrm{~m}$ isobath (highlighted in a thick black line), and thus representative of a steep shelf break. (b) Climatological monthly means for horizontal velocity vertical profiles projected along the ISW idealized propagation path, taken at green- and blue-filled circles in (a) (for May and October, respectively). (c) Same as (b) but for potential density vertical profiles. See text for more details.

ern border), rather than running directly across its main core (see also Fig. 1).

Climatological data from other monthly means show similar results, except for January and December, which are transition periods between both seasons. However, the vertically averaged currents shown in Fig. 9a (of the order of $10 \mathrm{~cm} \mathrm{~s}^{-1}$; see scaled arrow in black) are likely underestimated in the climatological data set. This is important since we can compare the mean SAR-derived propagation speeds in Fig. 9 with those obtained from a standard boundary value problem (BVP) with appropriate boundary conditions of the form

$$
\begin{aligned}
& \frac{\mathrm{d}^{2} \Phi}{\mathrm{d} z^{2}}+\left[\frac{N^{2}(z)}{(U-c)^{2}}-\frac{\mathrm{d}^{2} U / \mathrm{d} z^{2}}{U-c}\right] \Phi=0, \quad \Phi(0) \\
& =\Phi(-H)=0 .
\end{aligned}
$$

Note that in BVP 1 (the Taylor-Goldstein equation) $\Phi$ represents the vertical velocity modal structure; $H$ is the local depth, with $z$ being the vertical coordinate (directed upwards from the surface where $z=0$ ); $N$ is the Brunt-Väisälä frequency; and $U$ is the current vertical profile along the direction of wave propagation, assumed to have phase speed $c$ (see Miles, 1961; Smyth et al., 2011). Climatological profiles taken at appropriate locations along the waves' propagation paths were again used for currents and stratification (as shown in Fig. 9b and $\mathrm{c}$ and described in the previous section). Upon comparison, the $2.4 \mathrm{~m} \mathrm{~s}^{-1}$ estimated in May agrees reasonably well with the $2.3 \mathrm{~m} \mathrm{~s}^{-1}$ from the linear theory, but the $3.4 \mathrm{~m} \mathrm{~s}^{-1}$ in the October case study (see blue labels in Fig. 9) is well above the $2.5 \mathrm{~m} \mathrm{~s}^{-1}$ found from BVP 1 . This is likely because in situ currents are stronger than their climatological mean values, which were used to compute $U$ in BVP 1. In fact, that is precisely the case for the measurements reported in Brandt et al. (2002), which reveal currents (in November) an order of magnitude higher than those in Fig. 9 (i.e. around $1 \mathrm{~m} \mathrm{~s}^{-1}$; see their Fig. 1). Solving BVP 1 with a proxy for the measurements in Brandt et al. (2002) results in phase speeds between 3 and $3.5 \mathrm{~m} \mathrm{~s}^{-1}$, which are more consistent with the SAR. Drifter observations along the NECC further confirm that typical values for April and November display the NECC reversing character; they also reinforce that corresponding monthly means for near-surface currents are of the order of $1 \mathrm{~m} \mathrm{~s}^{-1}$ (see Lumpkin and Garzoli, 2005). Therefore, despite displaying the NECC seasonal character (i.e. the reversing of the current's main direction between May and October), which seems essential in explaining the SAR refraction patterns, the climatological data may be underestimating its true influence on the wave propagation speeds. 


\subsection{Semi-diurnal generation at the Amazon shelf break}

We now turn to the sources of the ITs in the study region. The SAR data set consistently reveals inter-packet distances comparable with mode- 1 semi-diurnal ITs (i.e. around $130 \mathrm{~km}$ ), regardless of the fortnightly tidal cycle, since ISWs are generated during neap and spring tides (see Table 1). Despite the remote appearance of the ISW field (i.e. its unusually large distance from the shelf break), its two-dimensional horizontal structure (best seen in Figs. 1 and 3) resembles that of the classical disintegration of an IT wave radiating from forcing bathymetry, just as in many other ISW hotspots like in the Bay of Biscay and the South China Sea (see e.g. New and da Silva., 2002; Buijsman et al., 2010b).

This hypothesis is further examined by quantifying how much of the surface tide is converted into internal motions at the tidal frequency by forcing bathymetry, and the corresponding propagation of the ITs. Conversion rates $(C)$ and energy fluxes $\left(\boldsymbol{F}_{\mathrm{E}}\right)$ are particularly useful parameters in numerical models accounting for ITs and have been found to be good indicators in global circulation models and in several other independent studies (see e.g. Gerkema et al., 2004; Shriver et al., 2012; Jeon et al., 2014; Kang and Fringer, 2012). Despite detailed numerical simulations being beyond the scope of the present study, we note that preliminary results (following from Buijsman et al., 2016) proved very useful in identifying IT sources and their spatial distributions. These numerical simulations were useful for guiding satellite acquisitions, which were requested specifically to survey ISWs and their sources in an unusually large study region.

Modelling data corresponding to a series of simulations performed with the 3-D global HYbrid Coordinate Ocean Model (HYCOM; see Bleck, 2002) were then examined to assess the main characteristics of the IW field energetics. HYCOM is a realistically forced ocean model, with both tidal and atmospheric forcing, and hence including the ocean's major current systems, such as the NBC or the NECC. The simulations used in this study refer to an annual period (from October 2011 to September 2012), and their tidal forcing includes the largest semi-diurnal and diurnal constituents (i.e. $M_{2}, S_{2}, N_{2}, K_{2}$, and $K_{1}, O_{1}, P_{1}, Q_{1}$ ), where a nominal horizontal resolution is set to $1 / 12^{\circ}$ at the Equator with 32 layers in the vertical direction. This particular data set is computed in a similar fashion as to Buijsman et al. (2016), whose detailed description may be found in Metzger et al. (2010), and Shriver et al. (2012). According to the SAR data we seek a priori to establish a semi-diurnal generation for the IT, whose energy budget is therefore extracted from HYCOM simulations with a cut-off period between 9 and $15 \mathrm{~h}$. These bandpass-filtered data are then used to compute the main IW field energetics, which will be discussed in the following paragraphs.

Figure 10 displays the depth-integrated and time-mean (i.e. over one full year) conversion rates $(C$, left panel) and energy fluxes $\left(\boldsymbol{F}_{\mathrm{E}}\right.$, right panel) for the semi-diurnal tides in the HYCOM simulations described above, as is usually done to obtain a two-dimensional horizontal view of the IT generation field (see e.g. Kang and Fringer, 2012; Buijsman et al., 2016). The maps presented in Fig. 10 are consistent with the SAR data (i.e. composite map of ISW crests in black solid lines), since strong ITs are generated over the steep slopes of the Amazon shelf break, which then propagate along two major pathways into the open ocean. As expected, the strongest conversion rates in the left panel are restricted to the shelf break, running along the $200 \mathrm{~m}$ isobath and decaying rapidly either in the onshore or offshore direction. Local maxima are coherent to each side of a small promontory (or headland - see reddish colours at locations A and B, near $44^{\circ} \mathrm{W}$ and $0^{\circ} \mathrm{N}$ ) from which the ITs emanate, and where $C$ values yield as high as $0.15 \mathrm{Wm}^{-2}$. Hence, this region is comparable to other known IT hotspots such as the Mascarene Ridge (see e.g. da Silva et al., 2015, and their Appendix A). We also note that the conversion rates along the $200 \mathrm{~m}$ isobath (where $C$ is strongest) are fairly uniform in the year-long period (considering mean values for different months, instead of the annual mean). In fact, tidal transports are invariantly (i.e. year-round) large precisely at $\mathrm{A}$ and $\mathrm{B}$, thus contributing to consistently large conversion rates (note that $C$ is proportional to the square of tidal transports). This is in agreement with ISWs being observed in this region throughout the year. Finally, a significant reduction in $C$ occurs between $\mathrm{A}$ and $\mathrm{B}$, thus emphasizing the distinction between these two separate generation sites, where tidal ellipses are large and currents run mainly in the cross-shelf direction - therefore ideal for elevated conversion rates from the surface tide into vertical baroclinic modes.

The depth-integrated energy fluxes ( $\boldsymbol{F}_{\mathrm{E}}$ in Fig. 10b), which essentially convey where the semi-diurnal IT energy is being held, are consistent with two major IT pathways emanating from A and B. Note that location A has somewhat stronger energy fluxes than B, in agreement with slightly longer ISW crests (see Fig. 5). Moreover, the propagation of the IT energy from the steep slopes of the Amazon shelf break is directed precisely towards the ISW sea surface manifestations seen on the composite map (Fig. 10b). It is interesting to see that the majority of the ISWs are first seen when $F_{\mathrm{E}}$ begins to decrease rapidly into the open ocean. This is probably a consequence of the filtered HYCOM data (which show only IWs at the semi-diurnal frequency) - hence, higherfrequency ISWs may become undetectable in HYCOM filtered data.

\subsection{Evolution and disintegration of the IT}

IT generation at the shelf break has proven to be consistent with an energetics analysis and is therefore a likely possibility in the study region. However, it is yet to be explained why the ISW evidence is found more than several hundred kilometres away from its forcing bathymetry (i.e. the shelf break) into the open ocean (see Fig. 1). We therefore proceed 
to some considerations concerning the evolution and disintegration of the IT.

As described in Gerkema and Zimmerman (1995), ITs evolve according to a balance between non-linear and dispersive effects. There are two fundamentally different sources for dispersion, which may arise either from rotational or nonhydrostatic effects. Longer waves like the IT are essentially controlled via rotational dispersion $\left(\mu=\frac{f^{2}}{\omega^{2}}\right.$, with $f$ being the Coriolis parameter and $\omega$ the wave frequency), which is much more efficient at the larger wavelengths and lower frequencies (ITs are essentially hydrostatic). The shorter ISWs, on the other hand, are much more sensitive to nonhydrostatic dispersion, which basically scales with $\delta=\frac{H_{\mathrm{t}}^{2}}{L^{2}}$. Note that $H_{\mathrm{t}}$ is a measure of the vertical extension of the waveguide and $L$ is representative of the wave's horizontal dimension (see also Helfrich and Grimshaw, 2008).

To balance dispersion, however, non-linearity also needs to be accounted for, which is typically parameterized as $\alpha=\frac{A}{H_{\mathrm{t}}}$, where $A$ is the wave amplitude (see e.g. Helfrich and Melville, 1990; Gerkema and Zimmerman, 1995). Nonlinear effects may be adjusted by changing either the wave amplitude or the thickness of the waveguide (usually taken as the thermocline). The wave amplitude is the most common choice in several theoretical and modelling studies, but in the present case it is the thermocline (i.e. $H_{\mathrm{t}}$ ) that seems to be the governing parameter. Note that a sharp density front was reported in Vlasenko et al. (2005), running closely along the ISW pathway associated with location A (see their Figs. 3.1 and 3.2 and our Fig. 1). This means that the thermocline's vertical extent (i.e. the waveguide) will decrease when moving offshore, as is shown by those authors and their in situ measurements.

In order to assess the effects of this environmental constraint on the disintegration process of the IT, we now present Figs. 11 and 12, which refer to a vertical density distribution running along the waves' propagation path. Figure 11a refers to ISWs associated with location A during the May season (i.e. between February and May). It shows a vertical density section corresponding to the green dashed line in Fig. 9, and calculated from a monthly mean as discussed in Sect. 3.1 for the NECC.

The overall view in Fig. 11a is that of a marked density front with an associated narrowing of the thermocline, which decreases more than $100 \mathrm{~m}$ between the shelf break and the open ocean. This result is actually quite similar to that provided by the in situ measurements in Vlasenko et al. (2005) and consequently builds on the consistency of our interpretations. Two vertical profiles (labelled P1 and P2 in Fig. 11b) help to characterize the waveguide vertical structure as it runs along the waves' propagation path, with P1 close to the $500 \mathrm{~m}$ isobath, and P2 just prior to the first SAR signatures seen in Fig. 1 (approximately at $3^{\circ} \mathrm{N}$ ). It is clear that the first evidence of the ISWs is closely related to the narrowing of the thermocline, which is simultaneously strengthened and brought closer to the surface (see P1 and P2 in Fig. 11b).

To further understand how this will influence the evolution of the IT, we now take $H_{\mathrm{t}}$ to be between the bolded isopycnals (in Fig. 11a), which were selected to be representative of the bulk of the thermocline seen in Fig. 11b. Figure 12a presents this parameter and again confirms how the waveguide is significantly decreased in height as the waves evolve into the open ocean, whereas the remaining panels in Fig. 12 illustrate its effect in the non-linear and dispersion parameters. We note that a semi-diurnal IT was assumed in the calculations (meaning $\omega$ corresponds to a period of $12.42 \mathrm{~h}$ ) with a nominal amplitude of $30 \mathrm{~m}$ (based on Figure 3.3 in Vlasenko et al., 2005, and needed to compute $\alpha$ ) and a horizontal dimension of $100 \mathrm{~km}$ (i.e. $L=100 \mathrm{~km}$ in $\delta$ ).

According to the results shown in Fig. 12, the decrease in the thermocline seen in Fig. 11 forces the non-linear parameter to increase to higher values (green lines in panels a and b). Also shown in Fig. 12b is a disintegration envelope for the IT based on the numerical results presented in Helfrich and Grimshaw (2008), which show that the disintegration process increases monotonically within those limits. Note that in this case $\alpha$ reaches this disintegration envelope approximately when the first ISWs appear in the SAR - i.e. between 3 and $4^{\circ} \mathrm{N}$ (marked as transitions between solid and dashed lines). At the same time, changes in the thermocline vertical extension are inconsequential to the nonhydrostatic dispersion seen in Fig. 12c, which is otherwise expected close to zero for the long wavelengths of the IT (as already mentioned). The same applies to the rotational (or Coriolis) dispersion, but for different reasons, since it is the proximity to the equator that dictates the low values of $\mu$.

Altogether, this means that increasing non-linearity (with no dispersion to compensate) will force the long IT to steepen and seek balance at the smaller wavelengths, up to the point where it may disintegrate into short-scale waves (Gerkema and Zimmerman, 1995). During the course of disintegration the nonhydrostatic dispersion will increase quite substantially (since $L$ drops by an order of magnitude) until balance may eventually lead to solitary-like waves. Note that lines in the dispersion panels (in Fig. 12) are therefore limited to the IT disintegration point (taken as $4^{\circ} \mathrm{N}$ ), beyond which both $\alpha$ and $\delta$ would have to accommodate the scales of the ISWs.

The climatological conditions met for ISWs originating from location A, between July and December (i.e. concerning the October season in Fig. 9), are quite similar to the previous case. A monthly mean for the October density field (this time running along the blue dashed line in Fig. 9) also reveals a similar decrease in the vertical structure of the waveguide with $H_{\mathrm{t}}$ decreasing accordingly (see blue line in Fig. 12a). All the remaining parameters also behave in the same fashion as discussed earlier. Note for instance that dispersion still remains weak, being indistinguishable from May, and is therefore shown in black for both cases. Nonlinearity in Fig. 12b (in a blue line) is also indicative of IT 

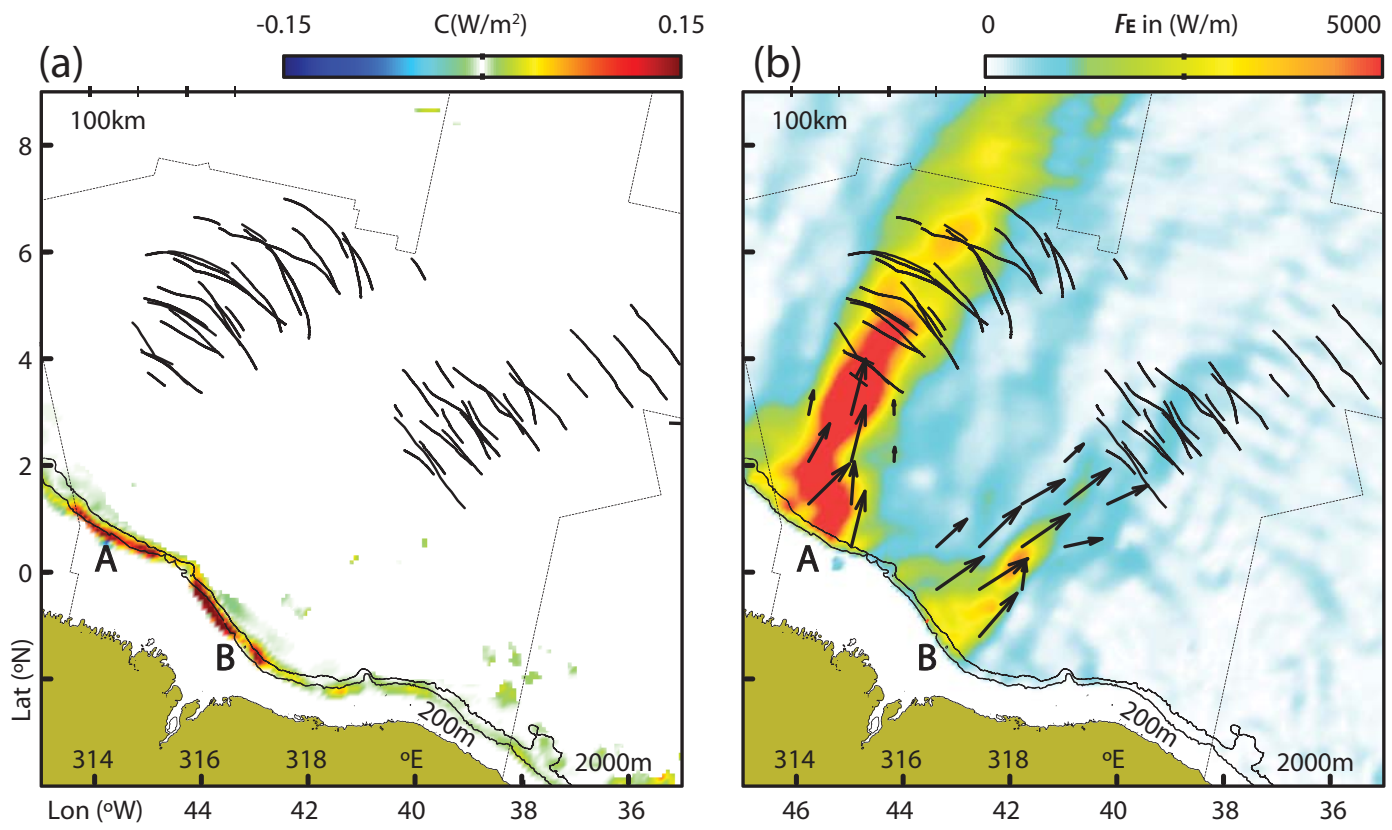

Figure 10. As in Fig. 1 with depth-integrated and time-averaged conversion rates $\left(C\right.$, in left panel) and baroclinic pressure fluxes $\left(\boldsymbol{F}_{\mathrm{E}}\right.$, in right panel) for the HYCOM simulations presented in the text (colour scales on top of each panel). Two major IT hotspots are seen in A and $\mathrm{B}$ where the surface tide is converted to baroclinic vertical modes, which then propagate in two different pathways to the open ocean.

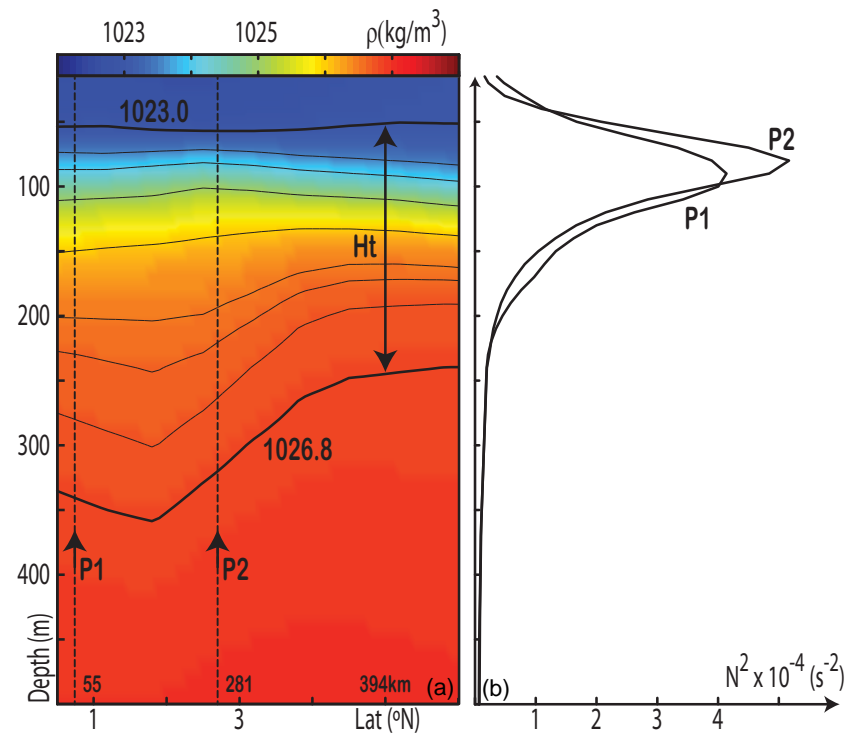

Figure 11. (a) May climatic vertical density section running along the green dashed line defined in Fig. 9 for generation site A. Selected isopycnals are also shown to highlight a density front. (b) Brunt-Väissälä vertical profiles taken at P1 and P2. Note that P1 is representative of the shelf break where ITs are being generated, while profile P2 is set just prior to the SAR ISW observations, where thermocline thickness decreases substantially.

disintegration and runs very closely to that of May (in a green line). In fact, regardless of the seasonal character in
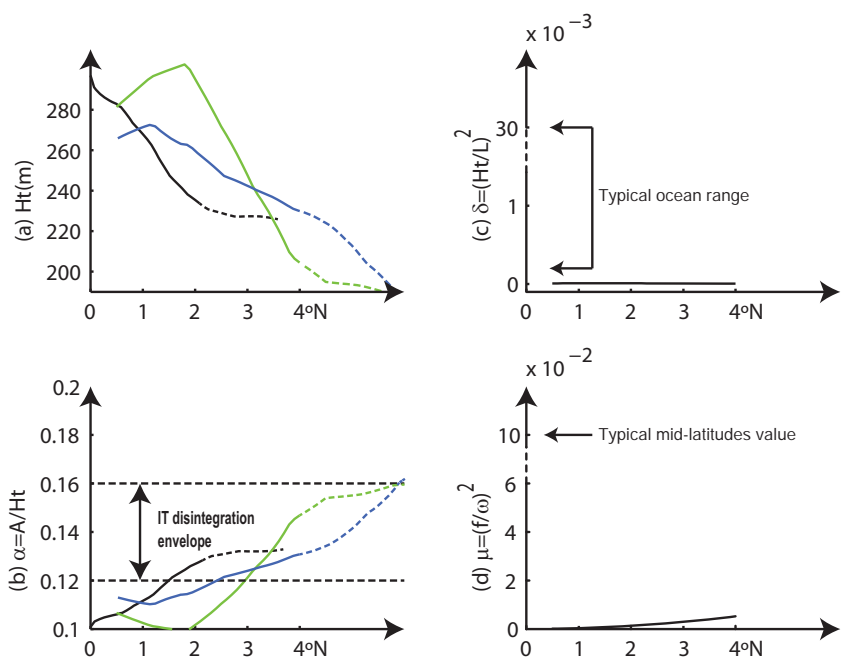

Figure 12. (a) Vertical extension of the waveguides calculated along the waves' propagation paths (in green, blue and black, according to dashed propagation paths in Fig. 9). (b) Same as panel (a) but for the non-linear parameter computed assuming an IT amplitude of $30 \mathrm{~m}$. (c) Nonhydrostatic dispersion for $L=100 \mathrm{~km}$. (d) Rotational dispersion for the semi-diurnal IT. Transitions to dashed lines in left panels indicate first SAR evidence of ISWs. Note broken vertical axes in right panels and typical ocean values showing comparatively weak dispersions in our study region. See text for more details.

the NECC, the vertical density structure along the ITs emanating from $\mathrm{A}$ seems to be consistent with its disintegration 
somewhere between 3 and $4^{\circ} \mathrm{N}$, and therefore in agreement with the earliest ISW signatures seen in the SAR.

The case for ITs emanating from B (see Fig. 1) is again very much alike. Following the same methodology as in Figs. 11 and 12, climatological data reveal a narrowing in the waveguide when moving along the waves' propagation path (see black dashed line in Fig. 9). The overall effect in the thermocline is as in the previous cases, with the waveguide becoming narrower, shallower and slightly stronger (see black line in Fig. 12a). This means that the non-linear parameter will increase beyond the disintegration threshold (note dispersion is again very weak) with reasonable agreement with the SAR observations seen to the north of $2^{\circ} \mathrm{N}$ (see Fig. $12 \mathrm{~b}$ with black dashed line again marking transition from the IT to ISWs).

In this study region the dispersion parameters are indeed very small. Note that $\mu$ is $O\left(10^{-2}\right)$ and $\delta$ is $O\left(10^{-4}\right)$, whereas midlatitudes values for $\mu$ are of the order of $10^{-1}$ and $\delta$ typically ranges from 0.2 to $30 \times 10^{-3}$ (assuming typical length scales for the IT) - see also Fig. 12c and $\mathrm{d}$ for comparisons. This means weak dispersion will be at play (see also Fig. 6 in Gerkema and Zimmerman, 1995). Therefore, the evolution of an IT assumed to radiate from the Amazon steep slopes is bound to break as soon as the non-linear effects come into play. According to Helfrich and Grimshaw (2008) the disintegration envelope is set here to be between 0.12 and 0.16 (in Fig. 12), but as these authors suggest it is not clear that this will always be the case. However, their trial run in the South China Sea is fairly close to our parameters, and we further note that shifting the disintegration boundaries does not change the good agreement between the SAR evidence and the waveguide influence on the IT disintegration process.

Finally, we comment on the measurements reported in Brandt et al. (2002), who had recognized the possibility of IT generation at the Amazon shelf break, but whose measurements were sparse and did not convey the tidal nature of the ISW packets. In fact, their inter-packet distances were reported around $70 \mathrm{~km}$, whereas SAR imagery shows typical values to be over $100 \mathrm{~km}$ (see Fig. 3). Therefore, rather than assuming a classical disintegration of the IT into ISWs (as is proposed here), they reasoned instead that different generation mechanisms might be at work, which were based on a large ageostrophic component of the NECC centred around $4.5^{\circ} \mathrm{N}$. We note, however, that the SAR clearly illustrates the semi-diurnal nature of the ISWs, which was not available to Brandt et al. (2002). Furthermore, ISWs are seen in the SAR much farther south of $4.5^{\circ} \mathrm{N}$, particularly at site $\mathrm{B}$, and thus not necessarily related with the ageostrophic component of the NECC.

In light of the available evidence, a late disintegration of the IT provides a more consistent hypothesis, assuming a significant amount of energy is transferred from the surface tide to the IT. This was indeed confirmed by independent modelling provided by the HYCOM data, whose vertically inte-
Table 2. Representative spatial averages for the depth-integrated and time mean conversion rates $\{C\}$ given in the HYCOM simulations for known hotspots with elevated ISW activity. See text for more details.

\begin{tabular}{lr}
\hline Known IT and ISW hotspots & $\begin{array}{r}\{C\} \text { in } \\
\left(\mathrm{W} \mathrm{m}^{-2}\right)\end{array}$ \\
\hline Amazon west flank & $\approx 0.1$ \\
Amazon east flank & $\approx 0.1$ \\
Andaman Sea & $\approx 0.1$ \\
Hawaiian Ridge & $\approx 0.1$ \\
Estremadura Promontory & $\approx 0.1$ \\
Bay of Biscay & $\approx 0.2$ \\
Luzon Strait & $\approx 0.2$ \\
Mascarene Ridge & $\approx 0.3$ \\
\hline
\end{tabular}

grated conversion rates are computed and presented in Table 2 for selected regions with large IT energy fluxes and known ISW activity (see e.g. Baines, 1982; Arbic et al., 2012; Jackson et al., 2012). Representative spatial averages were made for meaningful comparisons amongst the different regions - i.e. values noted under $\{C\}$. According to these results, the Amazon shelf shows large amounts of tidal energy being converted into the IT, which are of the same order of other known major hotspots of large ITs and elevated ISW activity, such as the Bay of Biscay, the Luzon Strait or the Mascarene Ridge (Indian Ocean).

\section{Summary and conclusions}

The Amazon shelf break in the tropical west Atlantic is a powerful hotspot for intense ISW sea surface manifestations. SAR revealed, for the first time, their two-dimensional horizontal structure and yielded important results concerning their generation and propagation characteristics. Two distinct generation sites were identified off the slopes of a small promontory, each associated with a different pathway of ISWs (see Fig. 1), but both consistent with an energetics analysis exhibiting high IT conversion rates. SAR images revealed some unusual characteristics of these largescale waves, such as their elevated propagation speeds and remote appearance several hundred kilometres away from the nearest forcing bathymetry. These large distances were explained in light of a late disintegration of the IT, based on standard parameters governing the balance between nonlinear and dispersion effects, and the decrease of the waveguide (i.e. thermocline) thickness along a pronounced density front (which ultimately relates to the geostrophic NBC and NECC). Finally, contributions from the NECC were also shown to be a likely explanation for the ISW seasonal propagation characteristics, using climatological data and SAR evidence, but a more substantiated approach would be welcome in order to confirm these results. Despite the first account 
of the two-dimensional horizontal structure of the ISW field given in this paper, there are several important questions that remain elusive and would likely benefit from high-resolution modelling and/or detailed in situ measurements.

Acknowledgements. The authors would like to acknowledge ESA project AOPT-2423 for providing SAR. We are grateful to the Brazilian CNPq (National Counsel of Technological and Scientific Development) project 313603/2013-8 "Internal wave systems in the tropical and western south Atlantic: from satellite views to local predictability" and the Federal University of Rio Grande (FURG), Brazil, for hosting sabbatical periods during the early stages of this paper. J. M. Magalhaes is grateful for an FCT research grant (SFRH/BPD/84420/2012). M. Buijsman was supported by the Office of Naval Research (ONR) under grant number ONRDC32025354. Finally, the authors greatly appreciate the revisions made by Leo Maas and Kevin Lamb, which significantly improved the quality of the manuscript, as well as fruitful discussions with Roger Grimshaw.

Edited by: E. J. M. Delhez

\section{References}

Alford, M. H., Peacock, T., MacKinnon, J. A., Nash, J. D., Buijsman, M. C., Centuroni, L. R., Chao, S.-Y., Chang, M.-H., Farmer, D. M., Fringer, O. B., et al.: The formation and fate of internal waves in the South China Sea, Nature, 521, 65-69, 2015.

Almeida-Filho, R., Miranda, F. P., Lorenzzetti, J. A., Pedroso, E. C., Beisl, C. H., Landau, L., Baptista, M. C., and Camargo, E. G.: RADARSAT-1 images in support of petroleum exploration: the offshore Amazon River mouth example, Can. J. Remote Sens., 31, 289-303, 2005.

Alpers, W.: Theory of radar imaging of internal waves, Nature, 314, 245-247, 1985.

Alpers, W. and Salusti, E.: Scylla and Charybdis observed from space, J. Geophys. Res., 88, 1800-1808, 1983.

Apel, J. R., Holbrook, J. R., Liu, A. K., and Tsai, J. J.: The Sulu Sea internal soliton experiment, J. Phys. Oceanogr., 15, 625-651, 1985.

Arbic, B. K., Richman, J. G., Shriver, J. F., Timko, P. G., Metzger, E. J., and Wallcraft, A. J.: Global modeling of internal tides within an eddying ocean general circulation model, Oceanography, 25, 20-29, 2012.

Azevedo, A., da Silva, J. C. B., and New, A. L.: On the generation and propagation of internal waves in the southern Bay of Biscay, Deep-Sea Res. Pt. I, 53, 927-941, 2006.

Baines, P. G.: On internal tides generation models, Deep-Sea Res. Pt. A, 29, 307-338, 1982.

Bleck, R.: An oceanic general circulation model framed in hybrid isopycnic Cartesian coordinates, Ocean Modell., 4, 55-88, 2002.

Brandt, P., Rubino, A., and Fisher, J.: Large-Amplitude Internal Solitary Waves in the North Equatorial Countercurrent, J. Phys. Oceanogr., 32, 1567-1573, 2002.

Buijsman, M. C., McWilliams, J. C., and Jackson, C. R.: Eastwest asymmetry in nonlinear internal waves from Luzon Strait,
J. Geophys. Res., 115, C10057, doi:10.1029/2009JC006004, 2010a.

Buijsman, M. C., Kanarska, Y., and McWilliams, J. C.: On the generation and evolution of nonlinear internal waves in the South China Sea, J. Geophys. Res., 115, C02012, doi:10.1029/2009JC005275, 2010b.

Buijsman, M. C., Ansong, J. K., Arbic., B. K., Richman, J. G., Shriver, J. F., Timko, P. G., Wallcraft, A. J., Whalen, C. B., and Zhao, Z.: Impact of internal wave drag on the semidiurnal energy balance in a global ocean circulation model, J. Phys. Oceanogr., doi:10.1175/JPO-D-15-0074.1, 2016.

da Silva, J. C. B., Ermakov, S. A., Robinson, I. S., Jeans, D. R. G., and Kijashko, S. V.: Role of surface films in ERS SAR signatures of internal waves on the shelf. 1. Short period internal waves, J. Geophys. Res., 103, 8009-8031, 1998.

da Silva, J. C. B. and Helfrich, K. R.: Synthetic Aperture Radar observations of resonantly generated internal solitary waves at Race Point Channel (Cape Cod), J. Geophys. Res., 113, C11016, doi:10.1029/2008JC005004, 2008.

da Silva, J. C. B., New, A. L., and Magalhaes, J. M.: Internal solitary waves in the Mozambique Channel: observations and interpretation, J. Geophys. Res., 114, C05001, doi:10.1029/2008JC005125, 2009.

da Silva, J. C. B., New, A. L., and Magalhaes, J. M.: On the structure and propagation of internal solitary waves generated at the Mascarene Plateau in the Indian Ocean, Deep-Sea Res. Pt. I, 58, 229-240, 2011.

da Silva, J. C. B., Buijsman, M. C., and Magalhaes, J. M.: Internal waves on the upstream side of a large sill of the Mascarene Ridge: a comprehensive view of their generation mechanisms, Deep-Sea Res. Pt. I, 99, 87-104, 2015.

Dunphy, M. and Lamb, K. G.: Focusing and vertical mode scattering of the first mode internal tide by mesoscale eddy interaction, J. Geophys. Res. Oc., 119, 523-536, 2014.

Egbert, G. D. and Erofeeva, S. Y.: Efficient inverse modelling of barotropic ocean tides, J. Oc. Atmos. Technol., 19, 183-204, 2002.

Ferrari, R. and Wunsch, C.: Ocean Circulation Kinetic Energy: Reservoirs, Sources, and Sinks, Ann. Rev. Fluid Mechan., 41, 253-282, 2009.

Garrett, C. and Kunze, E.: Internal tide generation in the deep ocean, Annu. Rev. Fluid Mech., 39, 57-87, 2007.

Garzoli, S. L. and Katz, E. J.: The forced annual reversal of the Atlantic North Equatorial Countercurrent, J. Phys. Oceanogr., 13, 2082-2090, 1983.

Gerkema, T. and Zimmerman, J. T. F.: Generation of Nonlinear Internal Tides and Solitary Waves, J. Phys. Oceanogr., 25, 10811094, 1995.

Gerkema, T., Lam, F.-P. A., and Maas, L. R. M.: Internal tides in the Bay of Biscay: Conversion rates and seasonal effects, Deep Sea Res. Pt. II, 51, 2995-3008, 2004.

Grisouard, N., Staquet, C., and Gerkema, T.: Generation of internal solitary waves in a pycnocline by an internal wave beam: a numerical study, J. Fluid Mech., 676, 491-513, 2011.

Guo, C., Vlasenko, V., Alpers, W., Stashchuk, N., and Chen, X.: Evidence of short internal waves trailing strong internal solitary waves in the northern South China Sea from synthetic aperture radar observations, Remote Sens. Environ., 124, 542-550, 2012. 
Helfrich, K. R. and Grimshaw, R. H. J.: Nonlinear Disintegration of the Internal Tide, J. Phys. Oceanogr., 28, 686-701, 2008.

Helfrich, K. R. and Melville, W. K.: Review of dispersive and resonant effects in internal wave propagation, in: The Physical Oceanography of Sea Straits, edited by: Pratt, L. J., Kluwer Academic Publishers, the Netherlands, 28, 391-420, 1990.

Hormann, V., Lumpkin, R., and Foltz, G. R.: Interannual North Equatorial Countercurrent variability and its relation to tropical Atlantic climate modes, J. Geophys. Res., 117, C04035, doi:10.1029/2011JC007697, 2012.

Ivanov, V. A., Ivanov, L. I., and Lisichenok, A. D.: Redistribution of energy of the internal tidal wave in the North Equatorial Countercurrent region, Sov. J. Phys. Oceanogr., 1, 383-386, 1990.

Jackson, C. R.: An Atlas of Internal Solitary-like Waves and Their Properties, 2nd Edn., Global Ocean Associates, Alexandria, VA, available online at: http://www.internalwaveatlas.com (last access: 26 July 2013), 560 pp., 2004.

Jackson, C. R., da Silva, J. C. B., and Jeans, G.: The generation of nonlinear internal waves, Oceanography, 25, 108-123, 2012.

Jeon, C., Park, J.-H., Varlamov, S. M., Yoon, J.-H., Kim, Y. H., Seo, S., Park, Y.-G., Min, H. S., Lee, J. H., and Kim C.-H.: Seasonal variation of semi diurnal internal tides in the East/Japan Sea, J. Geophys. Res. Oc., 119, 2843-2859, 2014.

Johns, W. E., Lee, T. N., Beardsley, R. C., Candela, J., Limeburner, R., and Castro, B.: Annual Cycle and Variability of the North Brazil Current, J. Phys. Oceanogr., 28, 103-128, 1998.

Kang, D. and Fringer, O.: Energetics of barotropic and baroclinic tides in the Monterey Bay area, J. Phys. Oceanogr., 42, 272-290, 2012.

Kozlov, I., Romanenkov, D., Zimin, A., and Chapron, B.: SAR observing large-scale nonlinear internal waves in the White Sea, Remote Sens. Environ., 147, 99-107, 2014.

Kudryavtsev, V., Akimov, D., Johannessen, J., and Chapron, B.: On radar imaging of current features: 1. Model and comparison with observations, J. Geophys. Res., 110, C07016, doi:10.1029/2004JC002505, 2005.

Lamb, K. G.: Internal Wave Breaking and Dissipation Mechanisms on the Continental Slope/Shelf, Annu. Rev. Fluid Mech., 46, 231-254, 2014.

Lumpkin, R. and Garzoli, S. L.: Near-surface Circulation in the Tropical Atlantic Ocean, Deep-Sea Res. Pt. I, 52, 495-518, 2005.

Magalhaes, J. M. and da Silva, J. C. B.: SAR observations of internal solitary waves generated at the Estremadura Promontory off the west Iberian coast, Deep-Sea Res., Pt. I, 69, 12-24, 2012.

Mercier, M. J., Mathur, M., Gostiaux, L., Gerkema, T., Magalhaes, J. M., da Silva, J. C. B., and Dauxois, T.: Soliton generation by internal tidal beams impinging on a pycnocline: Laboratory experiments, J. Fluid Mecha., 704, 37-60, 2012.

Metzger, E. J., Hurlburt, H. E., Xu, X., Shriver, J. F., Gordon, A. L., Sprintall, J., Susanto, R. D., and van Aken, H. M.: Simulated and observed circulation in the Indonesian Seas: $1 / 12^{\circ}$ global HYCOM and the INSTANT observations, Dyn. Atmos. Oc., 50, 275-300, 2010.

Miles, J. W.: On the stability of heterogeneous shear flows, J. Fluid Mech., 10, 496-508, 1961.

Moum, J. N., Klymak, J. M., Nash, J. D., Perlin, A., and Smyth, W. D.: Energy Transport by Nonlinear Internal Waves, J. Phys. Oceanogr., 37, 1968-1988, 2007.
New, A. L. and da Silva, J. C. B.: Remote-sensing evidence for the local generation of internal soliton packets in the central Bay of Biscay, Deep-Sea Res. Pt. I, 49, 915-934, 2002.

Osborne, A. R. and Burch, T. L.: Internal Solitons in the Andaman Sea, Science, 208, 451-460, 1980.

Ramp, S. R., Chiu, C. S., Kim, H.-R., Bahr, F. L., Tang, T.-Y., Yang, Y. J., Duda, T., and Liu, A. K.: Solitons in the northeastern South China Sea part I: Sources and propagation through deep water, IEEE, 29, 1157-1181, 2004.

Ray, R. D. and Cartwright, D. E.: Estimates of internal tide energy fluxes from TOPEX/Poseidon altimetry: Central North Pacific, Geophys. Res. Lett., 28, 259-262, 2001.

Sherwin, T. J., Vlasenko, V. I., Stashchuk, N., Jeans, D. R. G., and Jones, B.: Along-slope generation as an explanation for some unusually large internal tides, Deep-Sea Res. Pt. I, 49, 1787-1799, 2002.

Shriver, J. F., Arbic, B. K., Richman, J. G., Ray, R. D., Metzger, E. J., Wallcraft, A. J., and Timko, P. G.: An evaluation of the barotropic and internal tides in a high-resolution global ocean circulation model, J. Geophys. Res., 117, C10024, doi:10.1029/2012JC008170, 2012.

Shroyer, E. L., Moum, J. N., and Nash, J. D.: Mode 2 waves on the continental shelf: Ephemeral components of the nonlinear internal wave field, J. Geophys. Res., 115, C07001, doi:10.1029/2009JC005605, 2010.

Smyth, W. D., Moum, J. N., and Nash, J. D.: Narrowband oscillations in the upper equatorial ocean, Part II: Properties of shear instabilities, J. Phys. Oceanogr., 41, 412-428, 2011.

Thompson, D. R. and Gasparovic, R. F.: Intensity modulation in SAR images of internal waves, Nature, 320, 345-348, 1986.

Valente, A. S. and da Silva, J. C. B.: On the observability of the fortnightly cycle of the Tagus estuary turbid plume using MODIS ocean colour images, J. Mar. Syst., 75, 131-137, 2009.

Vlasenko, V. and Alpers, W.: Generation of secondary internal waves by the interaction of an internal solitary wave with an underwater bank, J. Geophys. Res., 110, C02019, doi:10.1029/2004JC002467, 2005.

Vlasenko, V., Stashchuk, N., and Hutter, K.: Baroclinic Tides: Theoretical Modeling and Observational Evidence, Cambridge University Press, New York, 351 pp., 2005.

Wisser, D., Fekete, B. M., Vörösmarty, C. J., and Schumann, A. H.: Reconstructing 20th century global hydrography: a contribution to the Global Terrestrial Network-Hydrology (GTN-H), Hydrol. Earth Syst. Sci., 14, 1-24, doi:10.5194/hess-14-1-2010, 2010.

Zhang, S., Alford, M. H., and Mickett, J. B.: Characteristics, generation and mass transport of nonlinear internal waves on the Washington continental shelf, J. Geophys. Res. Oceans, 120, 741-758, doi:10.1002/2014JC010393, 2015.

Zhao, Z., Klemas, V., Zheng, Q., and Yan, X.-H.: Remote sensing evidence for the baroclinic tide origin of internal solitary waves in the northeastern South China Sea, Geophys. Res. Lett., 31, L06302, doi:10.1029/2003GL019077, 2004.

Zhao, Z., Alford, M. H., and Girton, J. B.: Mapping low-mode internal tides from multisatellite altimetry, Oceanography, 25, 42-51, 2012. 